\title{
Implications of Interrelationship among Four Language Skills for High School English Teaching
}

\author{
Chengyu Nan \\ Yanbian University, Yanji, Jilin, China
}

\begin{abstract}
Theoretically, four language skills of listening, speaking, reading and writing are interrelated and interactive in real communication. According to the system theory, the improvement of whole language ability can not be achieved by a simple combination of the four skills, but results from the interaction and coordination among the four skills. On the basis of some theories of physiology and psychology as well as principles of system theory, this paper analyzes the interrelationship among four language skills and finds that they have close and strong an impact upon one another. Then the paper inquires into the necessities and feasibility of improving overall English language skills of high school students by comprising four language skills in a more economic and effective way.
\end{abstract}

Index Terms - system theory, learning theory, language skills, English teaching, positive transfer

\section{INTRODUCTION}

English Curriculum Standards for Nine-Year Compulsory Education (2011) requires that students should improve comprehensive language proficiency for real communication since four language skills are interrelated and facilitate one another in language learning and communication. Therefore, listening, speaking, reading and writing are not only learning contents for high school students but also learning tools and strategies for them.

Four language skills should be improved at the same time in language learning but their development is sometimes in imbalance. For the students, listening is more difficult than reading, and production is more difficult than understanding. For example, when listening, they cannot understand the same article, or the same sentence or even the same word which they can understand when reading; they can understand an article, but cannot use it or use appropriately. Therefore, it's important to explore the close relationship and impact among four language skills in order to find some effective ways of integrating them.

Previous research on four language skills of listening, speaking, reading and writing can be classified into two kinds, the relationships between two of the skills and teaching of one of the skills based on the relationships between two skills or relationship between input and output or between oral and written skills. Teaching modes of college English speaking, listening, reading or writing has been explored respectively based on input and output hypothesis (Han, 2016; Guan, 2015; Liu, 2014; Shen, 2012; Zheng, 2010). Zhao (1980) and Zhang (1995) have discussed the importance of developing both oral and written skills in college English teaching. Yang (1991) and Wu (1998) have explored how to develop English listening comprehension and Gao (2001) oral English proficiency of college students on the basis of understanding the interrelationship between speaking and listening. As for reading and writing relationships, Stotsky (1983) reviewed some correlational and experimental studies and Eckhoff (1983) carried out a study whose results show that the writing of children contains features of their reading texts. Shanahan discussed the nature of the reading-writing relation (1984) and the impact of writing instruction on learning to read (1980). Flower (1988) called for more studies on the active strategies of writers and readers and their relationships. Krashen (2012) claimed that writing style is not from writing experience but from reading. Most of the research in China based on reading-writing relationship has focused on how to improve English writing skills of high school students (Cai, 2009; Zhang, 2014; Cheng, 2016), but only a few on how to improve reading comprehension (Yang \& Dong, 2010). Relationship between listening and reading has been discussed in details by (Zou, 1988; Lin, 1996; Nan, 1997) and Wei (1994), Yang (2006) and Zhang (2012) have conducted experimental studies on how to develop English listening comprehension by integrating reading in teaching. The distance and relationship between speaking and writing (Cook-Gumperz \& Gumperz, 1981; Akiannso, 1982; Chen, 1991) as well as the influence of English oral proficiency on writing (Bereiter \& Scardamalia, 1982; Wang, 2007; Tang, 2011; Feng, 2017) has been also studied by a few scholars. The interrelationship among four language skills has been discussed in general by $\mathrm{Xu}(2004)$ and $\mathrm{Lu}(2006)$.

\section{RATIONALE}

From the physiological point of view, several different perceptions are involved in communication to perform linguistic activities of listening, speaking, reading and writing which are correlated with one another and form a whole. 
When certain communicative activity is performed, the relevant sense organs as well as other sense organs are involved. For instance, sense of hearing and kinesthesis are active in the process of reading. "Reading is the process of converting what are seen to what are heard and what are pronounced" (Zhu, 1997). Sense of sight and kinesthesis are active in writing. When writing, we are also reading. We are reading schematic knowledge in mind in order to retrieve the appropriate schema for writing. After writing, we read to check our product. Sense of sight is active in listening. The result of hearing is often checked through sense of sight, especially when we ask or talk about one's surname in Chinese since Chinese is rich in homophones.

According to the wholeness principle of system theory, "everything is considered as one part of a whole which belongs to a part of a bigger whole. Therefore everything should be comprehended in the relationships between whole and whole, part and part, as well as whole and part" (Yang, 1987). Improvement of the whole of a system is not the sum of the improvement of individual parts, but the result of the coordination of the relationships between elements and proportionate relationships of the parts of the system. The integration principle, which is based on the wholeness principle, of the system theory, holds that "The function of a system is greater than the sum of the functions of its parts (Yang, 1987) as long as the parts of the system are combined organically and merged with each other.

According to the transfer theory of learning, if one learning facilitates another one, there exists positive transfer between them; if one learning interferes or blocks another one, there exists negative transfer. The development of the overall language ability comprising the four language skills depends on the positive transfer made among the skills when they are combined and coordinated organically. So it is necessary to probe into the connecting points of the four skills and make full use of the positive transfer made between them, which will lead to the comprehensive improvement of the four language skills as English Curriculum Standards for Nine-Year Compulsory Education (2011) requires.

\section{INTERRELATIONSHIP AMONG FOUR LANGUAGE SKILLS}

Among the four language skills of listening, speaking, reading and writing, listening and reading which are a successive process belong to linguistic comprehension while speaking and writing which are interrelated belong to linguistic production. According to system theory, linguistic comprehension and linguistic production are two aspects of communication in which speakers and listeners, readers and writers are interconnected and interconditioned in terms of psychological and cognitive processes as well as information transfer process since the same modals of information process and such subjective factors in information process as amount of vocabulary, semantic schema, cognitive ability, and such objective factors as contexts are involved in both linguistic comprehension and linguistic production. According to the language acquisition theory of psycholinguistics, linguistic comprehension priors to linguistic production. Linguistic comprehension is the basis for linguistic production since only adequate understanding can lead to effective expression while sound linguistic production will enhance linguistic comprehension.

\section{A. Relationship between Listening and Reading}

According to the wholeness principle and integration principle of system theory, better understanding of the interrelationship between listening and reading must be helpful in developing linguistic comprehension. On one hand, listening and reading, which are not only the basic ways of linguistic comprehension but also the important methods of acquiring linguistic knowledge, share the same process of psychological activity and of decoding. Listening and reading are receptive skills, but listeners and readers don't receive information passively through outside stimulus. Listeners and readers intake information actively by connecting the information with their prediction, experience and schematic knowledge, which involves surface understanding and deep comprehension. On the other hand, listening and reading are correlative and reinforce each other. First, listening can facilitate one's capacity of response to language, which leads to faster reading. Listeners have little or no control over the speed of the input of listening material and cannot pause or go back to work out the meaning of the heard material as can be done when reading and therefore need to process new information in a very short time and comprehend the real intention of the speakers. Such a fast and complicated thinking process can drive forward the development of the listeners' ability to respond quickly to the linguistic meaning. In return this ability of quick response is necessary for speed reading and accurate reading. Secondly, since reading is a psycholinguistic guessing game (Goodman, 1967), previous knowledge which is stored in brain as schema is needed to win the game. Through reading, the students can enlarge their schematic knowledge which is useful for improving listening comprehension. A lot of reading enables the students to get more input by exposing themselves to various kinds of linguistic material, to broaden their knowledge, to increase background knowledge and enrich schematic knowledge, linguistic and non-linguistic. The ability to make effective use of schematic knowledge can be strengthened in repeated application and the process of invoking prior knowledge will become automatic. So when listeners hear new information, they can activate related schema quickly and comprehend the meaning accurately. Thirdly, the large number of vocabulary the students get in reading enables them to improve their listening skills. Vocabulary size, vocabulary recognition and vocabulary prediction play vital roles in linguistic comprehension. Students can enlarge their vocabulary in reading by exposing themselves to a great deal of practical and contextual words. This kind of quantity accumulation can lead to quality change, that is, more reading will push forward the improvement of listening comprehension. Fourthly, microskills of listening and reading can be used interchangeably. The same process of psychological activities and cognitive approaches are involved in listening and reading so that 
similar microskills are adopted in listening comprehension and reading comprehension. These microskills can be implemented respectively in listening class and reading class and such skills as predicating, reference and looking for key words can be presented interchangeably so as to get better understanding both in listening and reading. Fifthly, reading provides more opportunities for students to think in English, which will improve listening comprehension. Students may find out the differences in thinking between English people and Chinese people when they read and then they can follow and react to different grammatical structures and idiomatic expressions quickly enough to better their listening comprehension.

\section{B. Relationship between Speaking and Writing}

Speaking and writing belong to productive ability. Speaking, performed via vocabulary, grammar rules, rhythm and intonation, indicates the students' linguistic competence, pragmatic competence and the ability to use these two kinds of competence quickly and appropriately under some pressure. Writing requires more logical thinking and complicated grammatical structures. Speaking and writing are interrelated and cause positive transfer each other. First, speaking activates writing in an indirect way. Improvement of writing does not depend on the development of writing skills only. "Oral acquisition of language also can help the improvement of writing." (Zhu, 1997) The improvement of certain language skill is the result of effective cooperation with other skills. More speaking enables the students to be more familiar with the linguistic material, that is, what is used often in speaking will be used fluently in writing. Secondly, more speaking can speed up writing. Speaking is limited in time so it should be done in a short time in which any revision and correction cannot be made. The speakers should have quick thinking and fast response. Therefore more speaking is useful for writing because it can develop the ability to use language, make the linguistic production a fluent process and speed up thinking. Thirdly, more writing will be useful in developing the ability to speak more appropriately. Writing is rarely limited in time but is limited in other ways. Reasonable composition, substantial content, accurate expression and strong logic are required in writing. More writing can enhance the students' ability of wording and phrasing, using language appropriately, expressing themselves logically and composing properly. All of these points will enable students to express their ideas more appropriately and accurately.

\section{Relationship between Listening and Speaking}

On one hand, listening is first and the process of input while speaking is second and the process of output in language acquisition. The more input of linguistic material and linguistic knowledge, the more accurate, more fluent and more various the output will be. On the other hand, listening as comprehensive ability belongs to the implicit process, while speaking as productive ability belongs to the explicit process. Therefore, they are two closely related but opposite processes of psychological acts in oral communication, one from surface structure to deep structure, another from deep structure to surface structure. What the speaker expresses is not only the subject the listener should perceive and understands, but also the trigger for the listener to conduct a series of complicated psychological activities for final expression. During this complicated process, listening and speaking is an interrelated continuum. First, listening and speaking prerequisite each other. One learns to speak by listening. One can express himself only if he understands what he hears; speaking is important as a signaling device to negotiate better listening. One can understand easily what he can speak fluently. Secondly, more listening provides real linguistic context and appropriate English for oral communication. Real linguistic context pushes the speaker and listener to long for mutual dependence and mutual communication. More listening ensures the good quality and large quantity of language material from which both of the speaker and listener can obtain a lot of accurate and appropriate English. This helps them establish an intuitive sense of the language and an ability to comprehend the different feelings of the speaker. Thirdly, more speaking enhances the internalization of new information. People acquire language while using it. More speaking enhances the intake and internalization of new information and ensures the creative use of language. Speaking without listening or listening without speaking cannot achieve the communication goal. Fourthly, listening and speaking test each other. Listening is examined in speaking, that is, the accuracy of listening and degree of mastering listening skills can be checked in oral expression. Accuracy of speaking can be examined through listening, that is, one can correct his pronunciation and check the appropriateness of lexical use in speaking.

\section{Relationship between Reading and Writing}

According to the system theory, reading and writing are two complementary parts of the written communication system. As Stotsky (1983) indicated that "better writers tend to be better readers, which better writers tend to read more than poorer writers, and that better readers tend to produce more syntactically mature writing than poorer readers.", reading and writing enhance each other. First, both reading and writing depend on schematic knowledge. Writers and readers use similar kinds of knowledge about language, knowledge about content, knowledge about genre conventions, knowledge about organization and structure (Aulls, 1985; Flood \& Lapp,1987; Kucer, 1987), which can strengthen a writer's ability to read and a reader's ability to write. From the psychological perspective, "Reading and writing share the same cognitive process of human beings' thinking." (Kucer, 1987 ) When reading and writing, people use schematic knowledge stored in their mind. Secondly, reading is the basis for writing. "Reading materials are the thinking bank for writing." (Kennedy, 2011) Through a lot of reading, students can broaden their thinking and enrich the writing content. They also can understand the difference between English text models and Chinese text models as well as the differences 
between English thinking models and Chinese thinking models. The result of this is that the students can understand the features of English text in expressing and transmitting the information. According to Smith (1983), reading like a writer allows one to actually become a writer. Reading will enhance the development of English writing skills. Thirdly, writing enhances reading. Writing is the best way to indicate and develop reading efficiency. According to the difficulties in writing, students will try to find relevant information in reading. Therefore, writing is necessary for reading more effectively with more specific purposes. Fourthly, textual knowledge used in writing enhances reading comprehension. While writing, people always pay special attention to the sense development and relations between parts and whole, parts and parts as well as between elements of each part. This kind of textual knowledge used in writing will lead to faster, more accurate and more effective reading.

\section{IMPLiCATIONS FOR High SCHOOL ENGLISH TEACHING}

Whole language ability is a system composed of the four basic language skills of listening, speaking, reading and writing, interwoven and integrated with one another. The development of any of the four skills depends on and can lead to the development of the rest and finally causes the improvement of overall language ability. Therefore, in order to develop whole language ability of high school students, English teaching should be based on the principles of system theory, with the more effective use of the positive transfer made between them, and ensure more integrated and comprehensive English teaching and learning.

\section{A. Comprehensive Arrangement of Teaching so as to Ensure the Integral Force of All the Skills}

In order to develop overall language ability, we can adopt the whole language approach by means of which four language skills can be presented respectively and integratedly. In teaching where certain language skill is presented, we can use other skills as either supplementary means or for feedback, for instance, speaking and writing skills can be presented in listening class or in reading class or vice verse. We can use a listening text as a model for the students' speaking, and a reading text as a model for the students' writing. Or we can construct a series of activities that use a varieties of skills in which one activity is closely linked thematically to the next. We can also provide students with such comprehensive activities as "listening and speaking" and "reading and writing", which will make learning English more motivating and make sure of realistic and communicative use of the language.

\section{B. Importance of Sufficient Listening for High School Students in English Learning}

The amount of vocabulary one has mastered plays a very important role in developing four language skills. Lack of vocabulary is one of the main causes of the underdevelopment of either language skill. Reading can help build vocabulary that helps listening comprehension. As for high school students, listening more can also enlarge vocabulary efficiently, which is very useful in remembering words. Therefore more listening can help these students get and memorize more words and information in a faster way. As a result the four language skills will develop more efficiently. A large number of vocabulary is also helpful in guessing the meaning of the words more accurately and efficiently, which can enhance and speed up reading comprehension. Listening more can also check and correct the pronunciation, which is vital in improving both speaking and listening comprehension.

\section{Discussion in Class so as to Develop Four Language Skills}

Discussion, the bridge connecting language input with output, reflects the change from teacher-centered teaching to learner-centered teaching. Discussion can be organized in reading class so that what is being read can be applied to oral expression and at the same time oral communication can enhance reading comprehension. Discussions adopted in writing class can "make writing a kind of social communication activity" (Zhang,1995). Learners can make comments on one another's first draft of writing or discuss the questions put forward in comments. This kind of cooperative writing enables the learners to get direct and timely opinions from others and then adopt the reasonable suggestions to revise their own writing. As a result the writing ability will be improved more effectively. Relationship of listening and speaking. Discussions after listening can check the efficiency of listening

\section{More Reading, so as to Overcome the Unfavorable Factors Affecting the Development of Other Skills}

Reading, a complicated information process in which active and profound thinking activities and creative abilities are required, can facilitate the development of other language skills. More reading materials in class and after class can contribute to high school students' English language learning since purposeful reading can encourage thinking and learning other language skills. Reading can help high school English learners to gain an understanding of patterns of discourse and connections between language and culture, which is the basis for mastering linguistic knowledge, obtaining information and improving the ability of language use. Therefore, improvement of reading skills can ensure a lot of optimized linguistic input as well as ways of obtaining more and better information. Organizing a lot of extensive reading in a conscious and planned way in the whole process of high school English teaching can realize qualitative change and lay a good foundation for the improvement of other skills. In the classroom, students do best with frequent and extended opportunities to read and write and when exposed to a body of literature that represents a variety of genres, topics, and styles (Comstock, 1992). Since reading affects overall learning, instruction does best to focus on both reading and writing (Ferris \& Snyder, 1986; Shanahan, 1984) 


\section{E. Writing in the Whole Teaching Process}

Writing is a essential part of English teaching but it is also a weak link of English teaching. Writing ability can be improved in two ways, increasing teaching hours of writing or presenting and practicing writing skills in other individual skill presenting classes. According to the realities of high school English teaching in China, it is hard to increase teaching hours. Therefore, to have more effective writing, writing skills should be presented in other parts of teaching, for instance, combining presentation of writing with the presentation of reading, esp. textual reading, is one of the best ways of improving writing skills. What's more, a sense of authorship can lead to the development of critical literacy in which the reader/writer moves past simply understanding the content of the text or using it as a model to be imitated and begins to question, test, shape and reshape it (Flower, 1990). During the process it is the "interplay of mind and text that brings about new interpretations, reformulations of ideas, and new learnings." (Langer, 1986). In the content areas, essay writing was found to be more beneficial than answering questions or taking notes regardless of students' prior knowledge (Newell, 1984).

\section{CONCLUSION}

Speaking, listening, reading and writing are interrelated and interdependent in real communication. According to the system theory and the transfer theory of learning, the improvement of whole depends on the coordination of relationships and ratios between the elements of the system. Four language skills constitute a system in which the four skills interweave and integrate. Improvement of this system cannot be achieved by a simple combination of the four subsystems, but results from interaction and coordination among four subsystems which depend on one another to various degrees. Listening is the basis for speaking, reading is a source for listening, listening and speaking facilitate reading and writing, and vice verse. Therefore, the basic principles of system theory should be adopted in high school English teaching in order to maximize the effects of teaching and learning. Four language skills should be combined organically and merged with one another so as to ensure English teaching becomes integrated and comprehensive. In this way, we can obtain optimal integration of language learning and improve high school English teaching more efficiently. Different language skills should be integrated organically in whole high school English teaching in order to prepare for real communication. This can make high school English teaching comprehensive by means of economic teaching and presentation and achieve effective teaching by "less time, more efficiency".

\section{REFERENCES}

[1] Akiannso, F. N. (1982). On the differences between spoken and written Language. Language and Speech, 25.2, 97-125.

[2] Aulls, M. W. (1985). Understanding the relationship between reading and writing. Educational Horizons, 64. Fall, 39-44.

[3] Bereiter, C. \& M. Scardamalia (1982). From conversation to composition: The role of instruction in a developmental process. In R. Glaser (eds.), Advances in instructional psychology (Vol. 2). Hillsdale, New Jersey: Lawrence Erlbaum, 1-64.

[4] Cai, Haosheng. (2009). On the application of reading-to-writing approach to English writing teaching in senior middle school. MA thesis, Fujian Normal University, Fuzhou, China.

[5] Chen, Jianmin. (1991). Distance between speaking and writing. Language Planning, 5, 40-41.

[6] Cheng, Cuicui. (2016). A case study of teaching English writing through reading in senior high school. MA thesis, Shandong Normal University, Jinan, China.

[7] Comstock, M. (1992). Poetry and process: The reading/ writing connection. Language Arts, 69.4, 261-267.

[8] Cook-Gumperz, J. J. \& J. Gumperz. (1981). From oral to written culture: The transition to literacy. In M. Whitman (eds.), Variations in writing. Hillsdale, New Jersey: Lawrence Erlbaum, 89-109.

[9] Eckhoff, B. (1983). How reading affects children's writing. Language Arts, 60.6, 607- 616.

[10] Feng, Qiaozhen. (2017). Application of combining speaking and writing to college English writing teaching from the perspective of memetics. MA thesis, Jilin University, Changchun, China.

[11] Ferris, J. A. \& G. Snyder. (1986). Writing as an influence on reading. Journal of Reading, 29.8, 751-756.

[12] Flood, J. \& D. Lapp (1987). Reading and writing relations: Assumptions and directions. In J. Squire (eds.), The dynamics of Language Learning. Urbana: National Conference in Research in English, 9-26.

[13] Flower, L. (1988). The Construction of purpose in writing and reading. College English, 50.5, 528-550.

[14] Flower, L. (1990). The Role of task representation in reading-to-write. In L. Flower, V. Stein, J. Ackerman, M. J. Kantz, K. McCormick, and W. C. Peck (eds.), Reading-to-write: Exploring a cognitive and social process. New York: Oxford University Press, 35-75.

[15] Gao, Mingxia. (2001). Interrelationship between listening and speaking and developing oral communication skills. MA thesis, Yanbian University, Yanji, China.

[16] Goodman, K. S. (1967). Reading: A psycholinguistic guessing game. Journal of the Reading Specialist, 6.4, 126-135.

[17] Guan, Aihua. (2015). Teaching mode of college English writing from the perspective of input and output theory. MA thesis, Harbin Normal University, Harbin, China.

[18] Han, Yumeng. (2016). College oral English teaching mode based on Output-driven and Input-enabled Theory. MA thesis, Harbin Normal University, Harbin, China.

[19] Kennedy, M. L. \& W. J. Kennedy. (2011). Writing in the disciplines: A reader and rhetoric for academic writers (7th edn.). London: Longman Publishing Group.

[20] Krashen, S. D. (2012). The power of reading: insights from the research. Auckland: Heinemann

[21] Kucer, S. B. (1985). The making of meaning: Reading and writing as parallel processes. Written Communication, 2, 317-336. 
[22] Kucer, S. B. (1987). The cognitive base of reading and writing. In J. Squire (eds.), The dynamics of language learning. Urbana: National Conference in Research in English, 27-51.

[23] Langer, J. A. (1986). Learning through writing: Study skills in the content areas. Journal of Reading, 29, 400-406.

[24] Lin, Changwang. (1996). Relevance of listening and reading in EFL teaching. Foreign Language Teaching and Research, 4, 44-47.

[25] Liu, Guilin. (2014). Teaching college English reading from the perspective of input and output Theory. MA thesis, Hunan Normal University, Changsha, China.

[26] Lu, Jinshao. (2006). Relationship among listening, speaking, reading and writing. Journal of Hubei Normal College, 5, $102-104$.

[27] Nan, Chengyu. (1997). Interrelationship between English listening and reading. Journal of Yanbian University, 4, 135-138.

[28] Newell, G. E. (1984). Learning from writing in two content areas: A case study /protocol analysis. Research in the Teaching of English, 18.3, 265-287.

[29] Rost, M. (1990). Listening in language learning. London: Longman.

[30] Seyler, D. U. (2011). Read reason write: An argument text and reader (10 ${ }^{\text {th }}$ edn.). New York: McGraw-Hill Higher Education.

[31] Shanahan, T. (1980). The impact of writing instruction on learning to read. Reading World, 19, 357-368.

[32] Shanahan, T. (1984). The nature of the reading-writing relation: An exploratory multivariate analysis. Journal of Educational Psychology, 76.3, 466-477.

[33] Shen, Yu. (2012). Teaching mode of college English listening from the perspective of input and output theory. MA thesis, Nanjing Normal University, Nanjing, China.

[34] Smith, F. (1983). Reading like a writer. Language Arts, 60.5, 558-567.

[35] Stotsky, S. (1983). Research on reading/writing relationships: A synthesis and suggested directions. Language Arts, 60.5, 627-638.

[36] Tang, Qiyao. (2011). Interaction between speaking and writing in college English writing. Journal of Southwest Agricultural University, 10, 134-137.

[37] Wang, Manhua. (2007). A study on the promotion of English writing by combining speaking and writing. MA thesis, Inner Mongolia Normal University, Huhhot, China.

[38] Wei, Shulan. (1994). Relationship between listening and reading and the influence of reading on listening. Journal of Hunan University, 2, 119-123.

[39] Wu, Nan. (1998). Teaching strategies of English listening and speaking based on listening-speaking relationship. Journal of Zhanjiang Normal College, 2, 116-118.

[40] Xu, Dejiang. (2004). An experimental study of overall language teaching of listening, speaking, reading and writing. MA thesis, Northeast Normal University, Changchun, China.

[41] Yang, Chunshi. (1987). System theory, information theory \& cybernetics. Beijing: China Broadcast and Television Press.

[42] Yang, Huiyuan. (1991). On listening and speaking. Language Teaching and Linguistic Studies, 1, 88-98.

[43] Yang, Mingming. (2006). On the reading-listening hypothesis in the development of listening competence. MA thesis, Sichuan University, Chengdu, China.

[44] Yang, Yonglin \& Yuzhen Dong. (2010). Writing through reading plus reading through writing--A new exploration of experiential teaching approach. Foreign Languages in China, 1, 13-21.

[45] Zhang, Ling. (1995). Relationship between oral and written language. Foreign Language World, 3, 13-16.

[46] Zhao, Shikai. (1980). Relationship between oral and written proficiency in foreign language teaching. Journal of Foreign Languages, 5, 16-19.

[47] Zhang, Jing. (2014). An empirical study of the application of reading-to-writing strategies to English writing in senior high school. MA thesis, Hunan Normal University, Changsha, China.

[48] Zhang, Meng. (2012). A study on pre-reading scripts to listening teaching in higher vocational college. MA thesis, Ocean University of China, Qingdao, China.

[49] Zheng, Tianjiao. (2010). Influence of listening on speaking from the perspective of input and output theory. MA thesis, China University of Petroleum, Qingdao, China.

[50] Zhu, Chun. (1997). Psychology in foreign language teaching. Shanghai: Shanghai Foreign Language Education Press.

[51] Zou, Weicheng. (1988). Relationship between listening and reading in FLT. Foreign Language World, 2, 5-7.

Chengyu Nan was born in Yanji, China in 1965. She received her Ph. D degree in Linguistics from Yanbian University, China in 2007.

She is currently a professor and academic chair of English education, Yanbian University, Yanji, China. Her research interests include FLT and comparative study of English and Korean language. She has published two books: English Education of Korean-Chinese (2004) and A Comparative Study of Tense and Aspect in Korean and English languages (2007). She has published some papers on English and Korean tense and aspect, word formation in Korean and English, teaching English to Korean-Chinese bilinguals, and HBV in Korean, Chinese and English.

Dr. Nan is a member of IAAL (International Association for Applied Linguistics), Asia TEFL (The Asian Association of Teachers of English as a Foreign Language), and KATE (Korea Association of Teachers of English) and vice-president of Chinese Society for Multilingualism and Multilingual Education affiliated to the International Association of Multilingual Education. 